\title{
Utilizando Ícones Inteligentes para Estabelecer Estratégias na Aprendizagem
}

\section{Using Smart Icons to Establish Learning Strategies}

\author{
Marina Micas Jardim \\ Aperfeiçoamento em Tecnologia da Informação, Instituto Federal do Espírito Santo (IFES). \\ marinamicas@gmail.com \\ orcid.org/0000-0001-7300-5791
}

\section{Flávia Ernesto de Oliveira da Silva Alves}

Programa de Pós-Graduação em História das Ciências e das Técnicas e Epistemologia

(HCTE), Universidade Federal do Rio de Janeiro (UFRJ)

flaviaernesto@gmail.com

orcid.org/0000-0001-7111-9234

Resumo. A descrição deste artigo remete a importância de criar uma opção de exibição para ícones inteligentes dos nossos arquivos digitais, tanto como meio organizador quanto centralizador de conteúdos para facilitar o processo da aprendizagem. A percepção da necessidade de reter informações vem desde a pré-história com pinturas rupestres nas paredes de cavernas e atualmente a única diferença é contida nos números binários mascarados pela linguagem computacional em paredes virtuais. Inferindo na necessidade de obter tecnologias que agreguem inteligência com aspectos humanos para que o auxílio vá além de repositórios digitais.

Palavras-chave: Cognição. Aprendizagem. Ícones inteligentes.

\begin{abstract}
The description of this article refers to the importance of creating the option to display smart icons of our digital files, both as an organizer medium and as a centralizer of information to facilitate the learning process. The perception of the need to save information comes from the prehistory with cave paintings on the caves' walls and currently the only difference is contained in binary numbers masked by computational language on virtual walls. Inferring to the need to obtain technologies that aggregate intelligence within human aspects such that the aid goes beyond digital repositories.
\end{abstract}

Keywords: Cognition. Learning. Smart icons. 
Recebido: 01/10/2018 Aceito: 27/10/2018 Publicado: 05/11/2018

\section{Introdução}

O desejo de transmissão do conhecimento estampa rochas frisando que a necessidade de compartilhar vem desde a época pré-histórica que de acordo com RODRIGUES (2014) narra a sua proficuidade prógona na comunicação humana.

(...) imagens gravadas, desenhadas ou pintadas sobre superfícies rochosas, consideradas entre as manifestações mais antigas da habilidade e pensamento humanos, apresentando-se como um dos únicos vestígios arqueológicos resultantes, parte das suas experiências, pensamentos e crenças. (RODRIGUES, 2014, p. 14)

Esse desígnio não se limitam somente em uma necessidade de um único ser, na tentativa de apenas se satisfazer, pois ao ato de transmitir uma informação suscita em ampliar o aprendizado para outros, e quiçá aprimorá-los.

É um patrimônio pré-histórico importante devido a quantidade e relevância de informações que ela pode fornecer sobre os nossos antepassados. Pode-se dizer que por meio da arte rupestre o homem adquire conhecimento sobre o modo de vida de seus ancestrais, em especial sobre os seus costumes, crenças, culturas e comportamentos. (MENESES e LAGE, 2014, p. 1)

Tais transferências de conhecimentos à um local em conformidade a tecnologia que temos, onde nossas rochas agora são os computadores com pinturas binárias. E "através do processamento de imagens pode contribuir de forma preponderante, pois com a segmentação a arte é capturada, podendo ser arquivada e disponibilizada para pesquisas", assim como qualquer outra informação, surgindo o que conhecemos hoje por big data. (MENESES e LAGE, 2014)

Big data para (STEPHENS-DAVIDOWITZ, 2018) é um conceito vago e intrínseco, sem definição numérica do grande ou pequeno, e transfere sua interpretação ao nosso cotidiano contemporâneo.

$\mathrm{Na}$ acepção do autor acima, o quantitativo não se destaca, e sim a qualidade criativa em que os dados foram analisados. Em deferência a essa observação notável, a criação de ícones inteligentes se fundamentam, pois em sua visualização transformam a organização dos arquivos em grafos num formato singular de explorar os arquivos em aspecto interativo e com significados congruentes.

Os arquivos na exibição da opção de ícones inteligentes se conectam e se sobrepõem de acordo com a intelecção cerebral na qual os estudos de MARQUES (2017 apud LURIA) são ponderados em exames clínicos de pessoas com lesões no hemisfério esquerdo do córtex. Obtendo a avaliação das lesões na região occipital-pariental em perturbação da organização simultânea de estímulos e das lesões na região fronto-temporal perturbando o sucessivo, a 
isso se originou os princípios pertinentes ao Modelo de Integração de Informações de Marques. Além de suas raízes históricas a esse modelo terem originado em fontes fisiológicas de habilidades especuladas por Spearman, elementos primários aos laços cerebrais concebidos por Thomson teriam como resultado formar habilidades de composições básicas cerebrais de acordo com Maxwell e aos problemas psicológicos que Thurstone observou em relação às habilidades humanas que não eram compreendidas. (MARQUES, 2017)

Com tais características humanas, os objetivos gerais na criação dos ícones inteligentes serão em agregar propriedades simultâneas e sucessivas, onde no simultâneo os arquivos terão "estimulação" ao serem sobrepostos um acima do outro de acordo com o versionamento dos arquivos de mesma autoria e foco. E aos sucessivos, tais "estímulos" serão conectados em relação às suas convergências identificadas através de tags, e quanto aos divergentes, novos grafos se formarão.

\section{Métodos}

A pesquisa é de natureza aplicada obtendo portanto finalidades imediatas com a criação de ícones inteligentes. O procedimento realizado foi de cunho bibliográfico, investigando entre uma coletânea acadêmica (teses, dissertações e artigos científicos), além de livros que envolvem a utilização das informações, ícones e dos conceitos organizacionais como alvo para mediar o aprendizado através de uma opção visual de exibição de arquivos. Portanto, seu objetivo será de explorar as informações que vêm sendo estudadas no meio acadêmico com um enfoque à criação de ícones inteligentes. (VIANNA, 2013)

\section{Resultados e Discussão}

$\mathrm{Na}$ discussão em propor a opção de exibir os arquivos em formas de ícones inteligentes, questões são envolvidas em favor de justificar sua existência. Por que eles deveriam possuir características humanas como a organização simultânea e sucessiva além de características emocionais e cognitivas? O que isso influenciará ao aprendizado? E terceiro, nosso avanço tecnológico viabiliza sua criação?

Iniciando a resposta da primeira questão, sim; os ícones inteligentes devem possuir traços humanos. Pois eles poderão amparar em relação às três dimensões humanitárias, que em aspecto filosófico (Popadiuk, 2003) retratam que "o homem é uma mente funcionando em estado emocional e com um conjunto de movimentos de estrutura complexa." justificando a existência de uma opção visual para auxiliar na tomada de decisão humana, pois diante a essa objeção frisada na observação abaixo, os ícones inteligentes podem se sobressair diante dessa turbulência.

Corroborando também a visão de como um elo entre o funcionamento fisiológico e morfológico cerebral dos estudos de Luria do córtex às informações simultâneas e sucessivas pela diligência de Marques (2017), torna-se pertinente na concepção de um modelo de 
integração de informação, que releva o formato da nossa necessidade a busca de informações com o "como" ela é processada internamente a nós.

Esse Modelo de Integração da Informação sintetiza que as informações vêm de dois grandes grupos de estímulos, o input externo (podendo ser visual, auditivo, etc) e o método de apresentação (que podem ser simultâneos e sucessivos). Após essa etapa, a informação é registrada no registro sensorial e repassa ao processamento central, onde neste, a informação é processada de forma isocrônica e contínua e se integra a um planejamento e tomada de decisão, finalizando com um output igualitariamente funcional que determina e organiza a informação que foi estimulada.

O modelo assume que os dois modos de processamento de informações estão disponíveis para o indivíduo. A seleção de um ou ambos os modos depende de duas condições: (a) o modo habitual do indivíduo de processamento de informações como os determinados por fatores socioculturais e genéticos, e (b) as exigências da tarefa. (Marques, 2017, p. 48)

Retornando aos estudos de CHOO (2003) percebeu-se também "os estágios da busca da informação e os vários elementos que estabelecem o contexto para o uso da informação" originando-se um modelo ao uso da informação, destacando-se três importantes propriedades: a informação é construída, dependentes "das estruturas cognitivas e emocionais do indivíduo"; a informação é situacional, influenciado pelo "meio social ou profissional ao qual o indivíduo pertence"; e a informação é dinâmica, na necessidade da busca e do uso da informação e "na maneira como interage com os elementos cognitivos, emocionais e situacionais do ambiente".

Pode-se perceber que o estudo acerca da informação é envolto à carência humana "da percepção do vazio cognitivo no qual o indivíduo exerce sua capacidade de dar sentido à situação", como relatou-se Choo (2003, p. 118) e que além desse feitio cognoscente há o complemento de Marques (2017, p. 44) "na observação de Luria que o córtex está envolvido em dois tipos de atividade integrada: simultânea e sucessiva". Portanto, finalizando a primeira pergunta a respeito dos ícones inteligentes possuírem características humanas, resulta que é plausível terem tais qualidades.

Na segunda questão; no que os ícones inteligentes influenciarão ao aprendizado? CHOO (2003) retratou como a informação é formada.

(...) as três arenas de uso da informação - criar significado, construir conhecimento e tomar decisões - são de fato processos interligados, de modo que, analisando como essas três atividades se alimentam mutuamente, teremos uma visão holística do uso da informação. (CHOO, 2003, p. 29)

A exibição na opção de ícones inteligentes poderá "criar significado" numa construção visual de conhecimentos que, por fim, resultará numa tomada de decisão em qual arquivo utilizar primeiro, assim como podemos presenciar na cativante rota em que a informação caminha quando percebemos a necessidade de buscá-las, agilizando e organizando o aprendizado a esse processo. 
Unindo os estudos de Marques (2017) com os de Choo (2003), cria-se um sistema informatizacional que sugere uma influência congruente quando lidamos com informações e aspectos humanos ao binômio cognitivo-emocional. Transparecendo na intercessão dos modelos pesquisados a valia de contextualizar a importância dos arquivos serem exibidos de acordo com a inteligência humana para dar sentido ao um aprendizado intuitivo guiado com a perspicácia computacional.

$\mathrm{Na}$ terceira questão, "nosso avanço tecnológico viabiliza sua criação?" um aplicativo, o Evernote, introduz a resposta sendo ele capaz de capturar letras em imagens para facilitar a busca, viabilizando os ícones inteligentes nas conexões entre as imagens, sendo esse um dos tipos de arquivos existentes para visualização. TORRES e CAMPOS (2014) relata essa funcionalidade notável.

O Evernote, entretanto, permite que o profissional tire proveito das duas realidades. Anotações feitas em papel podem ser digitalizadas através do smartphone ou diversos modelos de scanner compatíveis e automaticamente enviadas diretamente para uma conta ou bloco de notas específico no Evernote. Uma vez armazenada no aplicativo, anotações feitas em letra de forma passarão também a ser identificados e localizadas pelo sistema de buscas. (CAMPOS e TORRES, 2014, p. 510)

Assim como o aplicativo Evernote, sistemas web semânticos vêm tomando espaço em projetos como o do:

Semantic Scholar é um projeto do Allen Institute for Artificial Intelligence (AI2), fundada para conduzir pesquisas e engenharia de alto impacto no campo da inteligência artificial. Somos financiados por Paul Allen, cofundador da Microsoft, e liderado pelo Dr. Oren Etzioni, um pesquisador de renome mundial e professor no campo da inteligência artificial. (SEMANTIC SCHOLAR)

Projeto este que disponibiliza gratuitamente mais de 40 milhões de artigos científicos, além de impactar num recurso interessante que viabiliza a criação dos ícones inteligentes, que é a opção de visualizar como um autor foi influenciado para a elaboração de suas pesquisas, assim como ele tem influenciado nas pesquisas de outros, onde o Semantic Scholar exibe visualmente essas informações.

A decorrência da pesquisa propõe uma visualização para afeiçoar as informações numa exibição com ícones inteligentes, abaixo segue sua proposta na Figura 2, assim como as opções já existentes no sistema operacional Windows 10 na Figura 1 para exibição dos arquivos digitais, facultando dessa forma a criação de ícones inteligentes como opção para exibição de layouts dos nossos arquivos digitais em nossos computadores. 


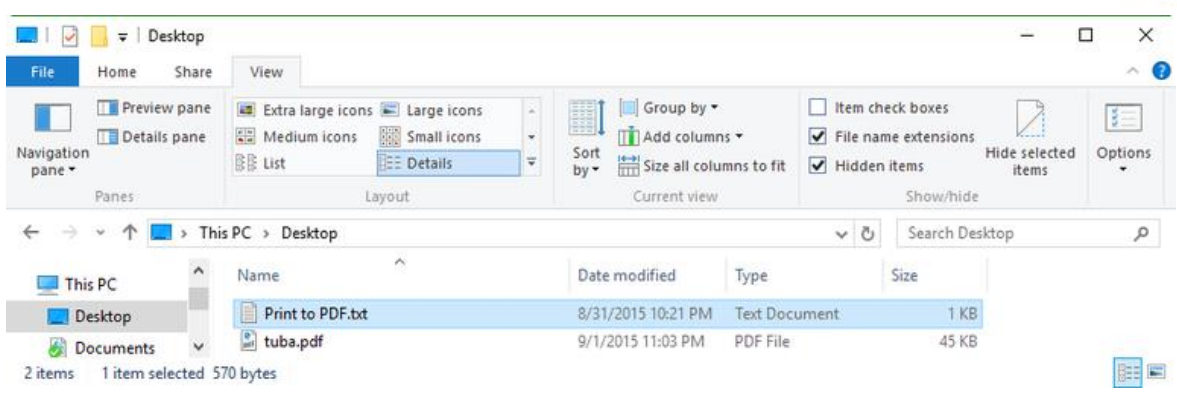

Figura 1. Layouts de exibição de arquivos existentes no Windows 10.

Fonte:https://www.techrepublic.com/article/get-to-know-file-explorers-ribbon-toolbarin-windows-10/


Figura 2. Proposta para exibição à Ícones inteligentes.

Fonte: JARDIM, M.M.

No Linux, existe a possibilidade de termos a visualização de informações detalhadas ao passar o mouse nele. Nos ícones inteligentes referido na pesquisa, também trarão recursos visuais ao passar o mouse nos arquivos, que transparecem os arquivos sobrepostos a eles e será exibido uma janela flutuante semelhante ao modo de exibição dos arquivos no Linux. Indo além dos efeitos ao passar do mouse, eles irão visualmente exibir as suas conexões com os outros arquivos correlatos. 


\section{Conclusões}

Conclui-se que existe tecnologia computacional viável para adequar uma exibição de arquivos em layout de ícones inteligentes com características humanas em relação à importância em que uma informação afeta em nosso sistema como pessoa, ficando necessário em pesquisas futuras as técnicas para posicionar os arquivos num formato de sobreposição, assim como implementar características de teorias dos grafos.

\section{Referências}

CHOO, C. W. A. A organização do conhecimento: como as organizações usam a informação para criar significado, construir conhecimento e tomar decisões. Tradução, Eliana Rocha. Apresentação editorial, Prof. Dr. Silvio Popadiuk. São Paulo: Editora Senac São Paulo, 2003.

MARQUES, C. V. M. EICA - Estruturas Internas Cognitivas Aprendentes: um Modelo Neuro-Computacional instanciando o sistema pessoa em espaços dimensionais. 2017. 174p. Tese (Doutorado em Engenharia de Sistemas e de Computação) - Universidade Federal do Rio de Janeiro, Rio de Janeiro, 2017.

MENESES, F. G. A. and LAGE, M. Segmentação de imagens de arte rupestre utilizando o sistema de coordenadas estelares. In: XXVII CONFERENCE ON GRAPHICS, PATTERNS AND IMAGES (SIBGRAPI 2014). Rio de Janeiro - RJ: agosto de 2014.

RODRIGUES, P. R. A. Motivo Rupestre como indicativo cronológico: Análise morfológica, contextual e intercultural. 2014. 115f. Dissertação (Mestrado em Arqueologia) - Universidade Federal do Piauí, Teresina, 2014.

SEMANTIC SCHOLAR. P. Allen (co-fund.). Projeto do Instituto Allen para a inteligência artificial (AI2). Disponível em: <https://www.semanticscholar.org/>. Acesso em: 09 jul. 2018.

SHULTZ, Greg. Get to know File Explorer's Ribbon toolbar in Windows 10. Disponível em: <https://www.techrepublic.com/article/get-to-know-file-explorers-ribbon-toolbar-inwindows-10/ $>$. Acesso em: 04 jun. 2020.

STEPHENS-DAVIDOWITZ, S. Todo mundo mente: O que a internet e os dados dizem sobre quem realmente somos. Tradução, Wendy Campos. Rio de Janeiro: Alta Books, 2018.

TORRES, A. A. L. and Campos, V. Evernote como ferramenta de organização de informações em saúde. Revista Eletrônica Gestão \& Saúde, v. 5, n. 2, p. 501-13, 2014. 
VIANNA, C. T. Classificação das Pesquisas Científicas - Notas para os alunos. Florianópolis, 2013, 2p. 